\title{
Espaço-Temporalidade dos Focos de Calor na Região Metropolitana de Maceió
}

\author{
Eli Moisés dos Santos Silva ${ }^{1}$ (D), Washington Luiz Félix Correia Filho ${ }^{1}$ (D), \\ José Francisco de Oliveira Júnior $^{1}$ (D), Heliofábio Gomes Barros ${ }^{1}$ (D), Micejane da Silva $\operatorname{Costa}^{1}$ (D), \\ Givanildo de Gois $^{2}$ (D), Nivaneide Alves de Melo Falcão ${ }^{3}$ (D) \\ ${ }^{1}$ Instituto de Ciências Atmosféricas, Universidade Federal de Alagoas, Maceió, AL, Brasil. \\ ${ }^{2}$ Programa de Pós-Graduação em Tecnologia Ambiental, Universidade Federal Fluminense, \\ Volta Redonda, RJ, Brazil. \\ ${ }^{3}$ Instituto de Geografia, Desenvolvimento e Meio Ambiente, Universidade Federal de Alagoas, \\ Maceió, AL, Brasil.
}

Recebido em: 28 de Junho de 2020 - Aceito em: 22 de Dezembro de 2020

\begin{abstract}
Resumo
Este trabalho avaliou as queimadas e os incêndios na Região Metropolitana de Maceió (RMM) via dados de focos de calor (FC) disponíveis no BQueimadas para no período de 1999 a 2019. A série temporal de focos calor foi submetida às análises estatísticas descritivas e multivariadas (Análise de Agrupamento - AA) juntamente com Vegetation Health Index (VHI) aplicadas aos FC nos municípios da RMM. Com base no agrupamento hierárquico identificaram-se três grupos homogêneos (G1, G2 e G3) de FC e o município de Atalaia que não se agrupou (NA). Os Grupos G1 (145,5 \pm $7,77 \mathrm{FC})$ e G2 (28,5 $\pm 44 \mathrm{FC})$ apresentaram similaridades quanto à sazonalidade dos FC. Enquanto o Grupo G3 (91 \pm 7,07 FC) que inclui a capital Maceió, apresentou distribuição irregular espacialmente. Toda a variabilidade dos FC está associada às atividades agrícolas vigentes na RMM. Mas também, à negligência de ateio de material inflamável sobre a vegetação propicia aumento de incêndios e queimadas, principalmente na colheita da cana-de-açúcar.
\end{abstract}

Palavras-chave: focos de calor, áreas queimadas, análise multivariada, índice de saúde vegetativa.

\section{Spatial-Temporal of Fire Foci in the Metropolitan Region of Maceió}

\begin{abstract}
This work evaluated the burnings and fires in the Maceió Metropolitan Region (MMR) via Fire Foci (FF) data available in BQueimadas for the period 1999 to 2019. The FF time series was submitted to descriptive and multivariate statistical analysis (Cluster Analysis - CA) together with the Vegetation Health Index (VHI) applied to the fire foci in the municipalities of MMR. Based on the hierarchical grouping, three homogeneous groups (G1, G2 and G3) of FF were identified and the municipality of Atalaia was not grouped (NA). Groups G1 (145.5 $\pm 7.77 \mathrm{FF})$ and G2 (28.5 $\pm 44 \mathrm{FF})$ presented similarities regarding the seasonality of the foci. While Group G3 $(91 \pm 7.07 \mathrm{FF})$, which includes the capital Maceió, presented irregular distribution spatially. All the variability of the FF is associated with the agricultural activities in the MMR. But also, the negligence of atheism of flammable material on the vegetation propitiates an increase of fires and burns, mainly in the sugarcane harvest.
\end{abstract}

Keywords: fire foci, burned area, multivariate analysis, vegetation health index.

\section{Introdução}

O efeito destrutivo do fogo é comum em áreas rurais, urbanas e nos biomas existentes no Brasil, sendo que as principais causas são devidas às atividades agrícolas, pecuária, desmatamento, fatores climáticos, entre outros (Pereira e Silva, 2016; Correia Filho et al., 2019; Silva,

Autor de correspondência: Eli Moisés dos Santos Silva, elimoises97@hotmail.com 
2020; Oliveira Júnior et al., 2020). Em geral, as queimadas e os incêndios necessitam de monitoramento em tempo integral (Caúla et al., 2016; Carneiro e Alburquerque, 2019; Santos et al., 2020) e, nos últimos anos têm sido feito via satélites ambientais a partir da detecção de focos de calor (FC) e risco de incêndio (RI) via sensores orbitais (Caúla et al., 2015; Clemente et al., 2017).

Vale ressaltar a diferença entre as queimadas e os incêndios. A queimada é controlada e regulamentada pelo Governo Federal de acordo com o Código Florestal no artigo $\mathrm{n}^{\circ} 38$ da Lei $\mathrm{n}^{\circ} 12.651 / 12$, que abrange todas as atividades agrícolas, as Unidades de Conservação (UC) e as Áreas de Preservação Ambiental (APA) - (MMA, 2020). Em contrapartida, quando se perde o controle da queimada é considerado como incêndio, que resulta em danos socioambientais e efeitos indesejáveis (SEMARH, 2004; Lima et al., 2020). As queimadas e os incêndios aumentam a poluição atmosférica, causam a piora da qualidade do ar e, consequentemente, o aumento das internações por doenças respiratórias (Mollmann Júnior et al., 2013; Silva et al., 2020; Oliveira et al., 2020). O processo de combustão libera diversos poluentes, por exemplo, monóxido de carbono (CO), óxidos nitrosos $\left(\mathrm{NO}_{\mathrm{x}}\right)$, hidrocarbonetos (HC), Compostos Voláteis Orgânicos (COV), e partículas de aerossóis entre outros para o meio ambiente, tanto na emissão local como remota (Mazzoli-Rocha et al., 2008; Fernandes e Correia Filho, 2013; Mollmann Júnior et al., 2013). Além dos poluentes citados anteriormente, o material particulado $10 \mu \mathrm{m}\left(\mathrm{PM}_{10}\right)$ é proveniente das emissões veiculares e da queima de biomassa nas áreas rurais (Araújo e Rosário, 2020).

O Sensoriamento Remoto (SR) é uma das ferramentas utilizadas para a detecção de FC via uso de satélites ambientais, com o propósito de ampliar o monitoramento da perda das áreas vegetativas, sobretudo, o controle e proteção do patrimônio brasileiro (Clemente et al., 2017; Santos et al.,2020). Anteriormente, Clemente et al. (2017), baseado em dados disponibilizados de FC, investigaram sua periodicidade no bioma Mata Atlântica e apontaram que sua distribuição está atribuída a atividades antropogênicas e ao agravamento das condições de variabilidade climática, devido as fases quente (El Niño) e fria (La Niña) do El Niño-Oscilação Sul (ENOS) que foram responsáveis pelos maiores registros de FC no Estado do Rio de Janeiro.

Ainda com relação ao uso do SR, existem alguns índices de vegetação (IV) que auxiliam no monitoramento do risco de incêndios em resposta as mudanças do clima (Mariani et al., 2016; Gomes et al., 2017; Correia Filho et al., 2018; Barros Santiago et al., 2020), principalmente em condições de secas prolongadas e severas (Kogan, 2002; Gomes et al., 2017). Um destes índices, que é comumente utilizado, é o Vegetation Health Index (VHI), que avalia o estado gradativo da vegetação e evidencia os efeitos nocivos das queimadas, conforme atestado por
Mariani et al. (2016), Gomes et al. (2017), Costa et al. (2020), e Barros Santiago et al. (2020).

A preocupação das queimadas e dos incêndios tornou-se evidente nas últimas décadas, pois no Brasil, esse problema se agravou ao ponto de a poluição provocada pelos focos de incêndios e queimadas serem capazes de interferir de forma remota nas condições meteorológicas das grandes cidades e, principalmente nas regiões metropolitanas (RM) - (Araújo e Rosário, 2020). No caso da Região Metropolitana de Maceió (RMM), as queimadas são originadas a partir da queima da cana-de-açúcar para auxiliar na sua colheita (Mollmann Júnior et al., 2013; Correia Filho et al., 2019). A cana-de-açúcar é o principal vetor econômico do Estado de Alagoas (Gayoso, 2020).

Apesar de haver um controle das queimadas em função da produção da cana-de-açúcar disponibilizado pelo Instituto do Meio Ambiente (IMA) - (IMA, 2020). E, também, estudos sobre os efeitos da poluição oriunda das queimadas no Estado (Fernandes e Correia Filho, 2013; Mollmann Júnior et al., 2013). Porém, até o presente momento, não foram realizados estudos que mostrem a variabilidade espaço-temporal dos FC no RMM. Portanto, o objetivo é avaliar a variabilidade dos FC na RMM entre os anos de 1999 a 2019, visto que os FC afetam a poluição atmosférica e qualidade do ar e podem atingir as $\mathrm{UC}$ e as APA existentes na RMM.

\section{Materiais e Métodos}

\section{Área de estudo}

A RMM é constituída por 13 municípios: Atalaia, Barra de Santo Antônio, Barra de São Miguel, Coqueiro Seco, Maceió (Capital), Marechal Deodoro, Messias, Murici, Paripueira, Pilar, Rio Largo, Santa Luzia do Norte e Satuba. A população estimada da RMM é 1.330.291 habitantes (FNEM, 2017; IBGE, 2020a). A RMM está situada na mesorregião Leste Alagoano (Fig. 1) e possui uma área de $3.250 \mathrm{~km}^{2}$, que se estende pela latitude $9,13^{\circ}$ a $9,86^{\circ} \mathrm{S}$ e longitude $35,47^{\circ}$ a $36,22^{\circ} \mathrm{W}$, situada no bioma da Mata Atlântica (Zanini, 2020).

Os diversos sistemas meteorológicos de multiescala, por exemplo, Distúrbios Ondulatórios de Leste (DOL), Perturbação Ondulatória dos Alísios (POA), convecção local, circulações de brisas, Alta Subtropical do Atlântico Sul (ASAS) e os Vórtices Ciclônicos de Altos Níveis (VCAN) que determinam a distribuição espaço-temporal de chuva da RMM (Molion e Bernardo, 2002; Tenório et al., 2010; Pontes da Silva et al., 2011; Costa e Lyra, 2012; Oliveira Júnior et al., 2012; Lyra et al., 2014). As características geográficas do local, tal como a continentalidade, contribui para o aumento de umidade, e consequentemente, menor variação sazonal da temperatura do ar (Barros et al., 2012; Lyra et al., 2014). Dos quais classificam a área como "As", segundo método de Köppen-Geiger, atri- 


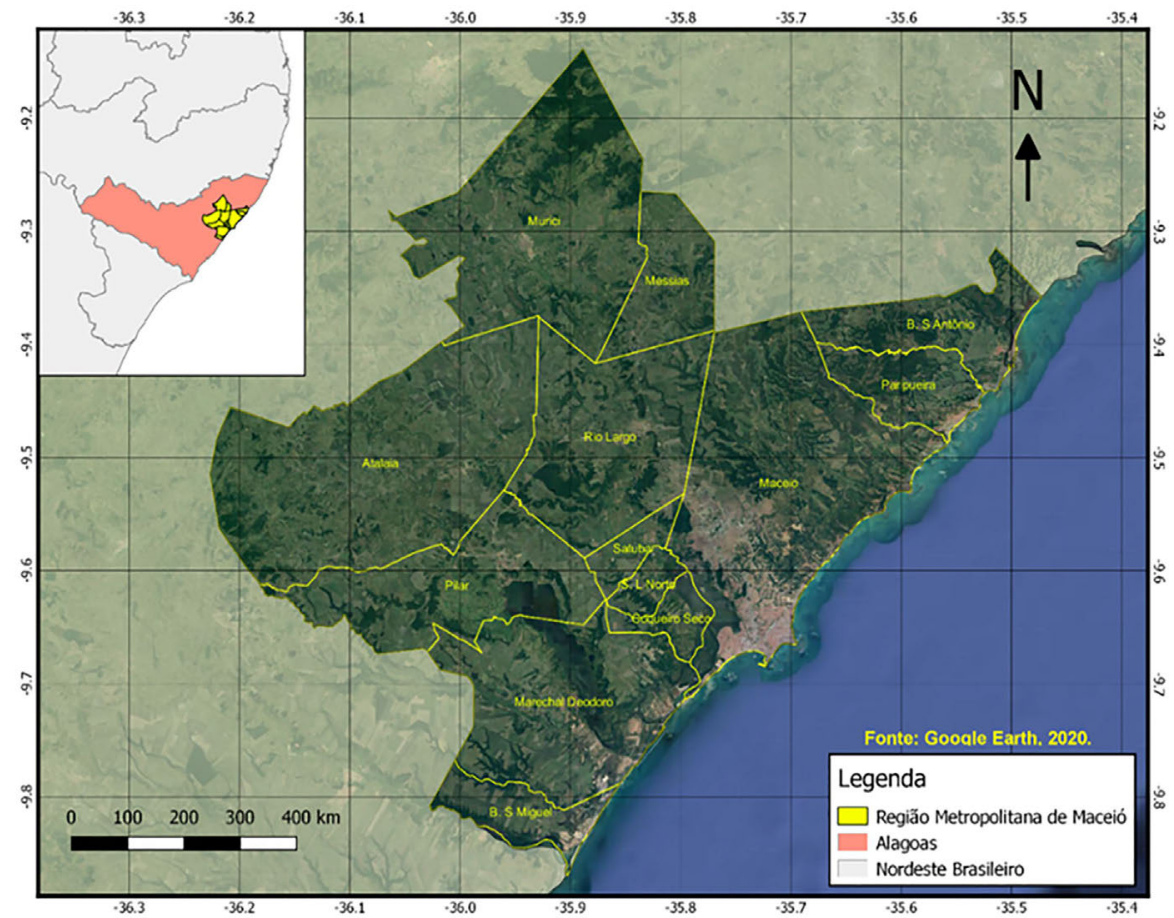

Figura 1 - Região Metropolitana de Maceió. Fonte: Google Earth (2020).

buído ao clima tropical com estação seca de verão (Barros et al., 2012). O acumulado de chuva anual varia entre $1000 \mathrm{~mm}$ a $1500 \mathrm{~mm}$ e o período chuvoso está compreendido entre os meses de abril a agosto (Barros et al., 2012, Nascimento et al., 2017).

\subsection{Série temporal dos FC}

O Banco de Dados de Queimadas (BDQueimadas) é um portal desenvolvido pelo Centro de Previsão do Tempo e Estudos Climáticos (CPTEC) no Instituto Nacional de Pesquisas Espaciais (INPE) que gerencia a ocorrência de FC e queimadas sobre a América do Sul a partir de satélites ambientais (CPTEC, 2016). No sistema de detecção de FC foram integrados nove satélites, sendo sete polares (NOAA-18, NOAA-19, METOP-B, TERRA, AQUA, NPP-Suomi e NOAA-20) e dois geoestacionários (GOES16 e MSG-3). Além dos satélites citados anteriormente, os satélites NOAA-12 (1998/2002) e AQUA (2002/dias atuais) foram utilizados para compor a série temporal (Setzer et al., 2019). Todos os satélites se limitam a encontrar frentes de fogo a partir de $30 \mathrm{~m}$ de resolução e com a ausência de nuvens (Carneiro e Albuquerque, 2019). Os dados de FC foram obtidos do BDQueimadas, disponibilizado no seguinte endereço eletrônico: http:// queimadas.dgi.inpe.br/queimadas/bdqueimadas/ (CPTEC, 2016). O período de estudo compreende os anos de 1999 a 2019, e utiliza os satélites NOAA-12 e AQUA como referência para os anos 1999 a 2002 e 2002 a 2019, respectivamente (INPE, 2020).

\subsection{Análise estatística}

A avaliação dos FC na RMM foi baseada na estatística descritiva (ED). Na ED utilizou-se a média (M), mediana (Md),máximo (Mx), mínimo (Mn), amplitude total (AT), Desvio Padrão (DP) e o Coeficiente de Variação (CV, \%) aplicada aos FC do período de estudo. Na estatística multivariada utilizou a técnica de CA na obtenção dos grupos homogêneos de FC na RMM. Para aplicação da técnica de CA foi utilizada a medida de distância Euclidiana, sendo calculada a partir do pacote "vegan" no software ambiente $\mathrm{R}$ versão 3.4-1(R Development Team, 2020). A distância Euclidiana é um método bastante conhecido na literatura baseado na medida de dissimilaridade (Benin et al., 2003; Albuquerque et al., 2006; Cargnelutti Filho et al., 2008), que neste caso avaliou a dissimilaridade entre os FC para cada município da RMM, sendo obtida a partir da Eq. (1):

$$
d_{E}=\sqrt{\sum_{J=1}^{P}\left(X_{i j}-X_{k j}\right)^{2}}
$$

em que $d_{E}$ é a distância euclidiana, $X_{i j}$ e $X_{i j}$ são as variáveis quantitativas em $j$ individual de $p$.

A determinação dos grupos foi avaliada via método hierárquico de Ward (1963) que indica o grau de homogeneidade e heterogeneidade entre os agrupamentos formados, conforme a Eq. (2): 


$$
W=\sum_{i=1}^{n} x^{2}-\frac{1}{n}\left(\sum x\right)^{2}
$$

em que $W$ indica homogeneidade e heterogeneidade entre os agrupamentos; $x$ é desvio padrão; $n$ é o número de valores analisados. Vale ressaltar que o somatório do quadrado dos desvios irá apontar o grau de homogeneidade e os números de grupos que apresentam semelhança entre si (Hair et al., 2005).

O método Ward obteve resultados satisfatórios em estudos anteriores na análise dos FC (Caúla et al., 2015;
Gois et al., 2020; Oliveira Júnior et al., 2020). Para validar a consistência do padrão de agrupamento hierárquico (dendrograma) foi usado o Coeficiente de Correlação Cofenética (CCC) - (Saraçli et al., 2013). O CCC mede o grau de preservação das distâncias emparelhadas pelo dendrograma resultante do agrupamento em relação às distâncias originais (Saraçli et al., 2013), com intervalo que varia entre 0 e 1 . Segundo Sokal e Rohlf (1962), quando o $C C C>0.7$ indica que o método de agrupamento é adequado para resumir a informação do conjunto de dados. O CCC é definido pela Eq. (3):

$$
C C C=r_{c o f}=\frac{\sum_{j=1}^{n-1} \sum_{j^{\prime}=j+1}^{n}\left(c_{j j^{\prime}}-\bar{c}\right)\left(f_{j j^{\prime}}-\bar{f}\right)}{\left(\sqrt{\sum_{j=1}^{n-1} \sum_{j^{\prime}=j+1}^{n}\left(c_{j j^{\prime}}-\bar{c}\right)^{2}}\right)\left(\sqrt{\sum_{j=1}^{n-1} \sum_{j^{\prime}=j+1}^{n}\left(f_{j j^{\prime}}-\bar{f}\right)^{2}}\right)}
$$

em que $\bar{c}$ e $\bar{f}$ são as médias aritméticas, definidas pelas Eqs. (4) e (5):

$$
\begin{gathered}
\bar{c}=\frac{\sum_{i=1}^{n} c_{i}}{n} \\
\bar{f}=\frac{\sum_{j=1}^{n} f_{i}}{n}
\end{gathered}
$$

em que $C C C$ é o coeficiente de correlação cofenético, $C$ é a matriz cofenética e $\bar{C}$ é a média da matriz cofenética, $f$ é a matriz fenética e $\bar{f}$ é a média da matriz cofenética, $n$ é o número de elementos.

\subsection{Vegetation Health Index (VHI)}

$\mathrm{Na}$ busca de compreender a variabilidade dos FC, analisou-se a saúde vegetativa a partir de mapas temáticos anuais do VHI, com objetivo de categorizar as secas na RMM. Para a extração do VHI, utilizaram-se os dados ambientais: 1) Normalized Difference Vegetation Index (NDVI), 2) Temperatura da Superfície Terrestre (TST), selecionando os anos de maior ocorrência. Em relação aos dados de NDVI e TST são provenientes do sensor MODIS, pertencentes ao conjunto de dados MYD13A2 e MYD11A2 da plataforma orbital AQUA da NASA, respectivamente. Ambas as bases de dados possuem resolução espacial de $1 \mathrm{~km} \times 1 \mathrm{~km}$ e temporal mensal, respectivamente (Didan, 2015; Wan et al., 2015). O NDVI pode ser obtido pela Eq. (6) (Tucker, 1979):

$$
N D V I=\left(\rho_{I V P}-\rho_{v}\right) /\left(\rho_{I V P}+\rho_{v}\right)
$$

em que $\rho_{I V P}$ e $\rho_{V}$ correspondem, respectivamente, às reflectâncias das bandas do infravermelho-próximo e vermelho. O índice NDVI varia de acordo com a atividade fotossintética das plantas e sua densidade na área considerada (pixel), entre -1 (superfícies como água e nuvens geralmente são inferiores a zero) $\mathrm{e}+1$ (corresponde ao maior vigor da vegetação).

Enquanto que o TST é obtido pela Eq. (2):

$$
T S T=(T S T-(T S T \times 0,02))-273,16
$$

em que TST é dado em Kelvin (K), e posteriormente convertido para Celsius $\left({ }^{\circ} \mathrm{C}\right)$.

O VHI é comumente utilizado na detecção de seca a partir da saúde vegetativa (Karnieli et al., 2010; Bento et al., 2018; Santiago et al., 2020), e é obtido pela Eq. (8):

$$
V H I=(0,5 \times V C I)+(1-0,5) \times T C I
$$

$\mathrm{O}$ valor de $V H I$ varia de acordo com a condição sem seca (favorável) a seca extrema (estresse), conforme a Tabela 1.

A obtenção do Vegetation Condition Index (VCI) e da Temperature Condition Index (TCI) mencionados no VHI será descrito a seguir. O VCI foi proposto por Kogan (1995) e normaliza o Normalized Difference Vegetation Index (NDVI) entre os valores mínimos e máximos, durante o período de estudo. Este índice destaca a possível

Tabela 1 - Classificação dos valores de VHI em termos de seca (Kogan, 2001)

\begin{tabular}{lc}
\hline Valores de VHI & Categorização da seca \\
\hline $\mathrm{VHI} \leq 10$ & Seca Extrema \\
$10<\mathrm{VHI} \leq 20$ & Seca Severa \\
$20<\mathrm{VHI} \leq 30$ & Seca Moderada \\
$30<\mathrm{VHI} \leq 40$ & Seca Leve \\
$40<\mathrm{VHI} \leq 50$ & Não ocorre seca \\
$\mathrm{VHI}>50$ & Saudável \\
\hline
\end{tabular}


diferença significativa ao longo do tempo, minimizando a influência da variabilidade espacial da vegetação entre diferentes coberturas vegetativas e as condições climáticas (Karnieli et al., 2010). O VCI é obtido pela Eq. (9):

$$
V C I=\left(\frac{\left(N D V I^{\prime}-N D V I_{\max }\right)}{\left(N D V I_{\max }-N D V I_{\min }\right)}\right) \times 100
$$

em que $N D V I^{\prime}$ é o valor médio do $N D V I$ de cada ano, $N D V$ $I_{\text {max }}$ e $N D V I_{\text {min }}$ representam o valor máximo e mínimo do período analisado, respectivamente.

Como adaptação ao VCI, o TCI permite estimar as condições térmicas de seca em superfície, baseado nos valores da Temperatura Superfície Terrestre (TST) (Eq. 10) - (Kogan, 1995).

$$
T C I=\left(\frac{\left(T S T_{\max }-T S T^{\prime}\right)}{\left(T S T_{\max }-T S T_{\min }\right)}\right) \times 100
$$

em que $T S T^{\prime}, T S T_{\max }$ e $T S T_{\min }$ se referem às temperaturas média, máxima e mínima doperíodo analisado, respectivamente.

\subsection{Seleção de episódios do ENOS}

Também se verificou a influência interanual do modo de variabilidade climática, ENOS, para avaliar sua influência na variabilidade dos FC na RMM. Para isto, utilizou-se o Oceanic Nino Index (ONI), correspondente à região 3.4, do Oceano Pacífico Tropical, referente à anomalia de Temperatura à Superfície do Mar (TSM). Maiores detalhes do ONI está disponível no site da NOAA/CPC
(National Oceanic and Atmospheric Administration/Climate Prediction Center) - (NOAA/CPC, 2020). Quando o ONI for superior a $0.5^{\circ} \mathrm{C}$ (inferior a $-0.5^{\circ} \mathrm{C}$ ) é classificado como El Niño ( La Niña) e suas respectivas categorizações (Muito Forte, Forte, Moderada, Fraca e Neutra) - (Huang et al., 2015).

\subsection{Dados de cultivo de cana-de-açúcar}

Os dados de área plantada (ha) de cana-de-açúcar da RMM foram obtidos no Instituto Brasileiro de Geografia e Estatística (IBGE) no período de 1999 a 2018. Os dados foram obtidos da plataforma SIDRA (https://sidra.ibge. gov.br/tabela/5457) - (IBGE, 2020b), organizados e correlacionados a área plantada de cana-de açúcar versus $\mathrm{FC}$ da RMM.

Todo o procedimento de extração das imagens VHI e dados de FC, manipulação e organização dos dados para a obtenção da estatística descritiva, aplicação da técnica de CA e a ilustração dos mapas foram realizados com o auxílio dos softwares ambiente $\mathrm{R}$ versão 3.4-1 (R Development Team, 2020), do Quantum GIS (QGIS) versão 3.4.6 (Qgis Core Team, 2017) e do Origin Pro.versão 8.69 (OriginLab, 2019).

\section{Resultados e Discussão}

\subsection{ED aplicada aos FC na RMM}

A Tabela 2 apresenta a ED dos FC da RMM durante o período de estudo. Neste período foram registrados 951 FC na RMM, com destaque para o município de Atalaia que apresentou o maior número de ocorrências de FC

Tabela 2 - Resultado da ED aplicado à série temporal dos FC acumulado entre o período de 1999-2019. As siglas correspondem aos termos: ID - Identificador, ATFC - Acumulado Total de Foco de Calor, PATFC - Percentual Acumulado Total de FC, M - Média, Md - Mediana, Mn - Mínima, Mx - Máxi-

\begin{tabular}{|c|c|c|c|c|c|c|c|c|c|c|}
\hline \multirow[t]{2}{*}{ ID } & \multirow[t]{2}{*}{ Municípios } & \multirow[t]{2}{*}{ ATFC } & \multirow[t]{2}{*}{ PATFC (\%) } & M & MD & $\mathrm{Mn}$ & $\mathrm{Mx}$ & $\mathrm{AT}$ & $\mathrm{DP}$ & \multirow{2}{*}{$\begin{array}{l}\text { CV } \\
(\%)\end{array}$} \\
\hline & & & & \multicolumn{6}{|c|}{$\left(\right.$ Focos. Ano- $\left.^{1}\right)$} & \\
\hline 1 & Atalaia & 250 & 26,29 & 11,90 & 8 & 2 & 34 & 32 & 8,14 & 68,39 \\
\hline 2 & B. de São Antônio & 44 & 4,63 & 2,10 & 1 & 0 & 5 & 5 & 1,61 & 76,82 \\
\hline 3 & B. de São Miguel & 21 & 2,21 & 1,00 & 0 & 0 & 5 & 5 & 1,34 & 134,16 \\
\hline 4 & Coqueiro Seco & 2 & 0,21 & 0,10 & 0 & 0 & 1 & 1 & 0,30 & 315,83 \\
\hline 5 & Maceió & 96 & 10,09 & 4,57 & 4 & 0 & 14 & 14 & 3,19 & 69,72 \\
\hline 6 & Marechal Deodoro & 86 & 9,04 & 4,10 & 5 & 0 & 9 & 9 & 3,05 & 74,43 \\
\hline 7 & Messias & 44 & 4,63 & 2,10 & 2 & 0 & 6 & 6 & 1,76 & 83,90 \\
\hline 8 & Murici & 151 & 15,88 & 7,19 & 6 & 1 & 30 & 29 & 6,86 & 95,41 \\
\hline 9 & Paripueira & 22 & 2,31 & 1,05 & 1 & 0 & 3 & 3 & 1,07 & 102,26 \\
\hline 10 & Pilar & 69 & 7,26 & 3,29 & 3 & 0 & 8 & 8 & 2,33 & 70,82 \\
\hline 11 & Rio Largo & 140 & 14,72 & 6,67 & 7 & 0 & 20 & 20 & 4,77 & 71,52 \\
\hline 12 & S. Luzia do Norte & 2 & 0,21 & 0,10 & 0 & 0 & 1 & 1 & 0,30 & 315,83 \\
\hline \multirow[t]{2}{*}{13} & Satuba & 24 & 2,52 & 1,14 & 1 & 0 & 5 & 5 & 1,39 & 121,51 \\
\hline & Total & 951 & 100 & 45,28 & 38 & - & - & - & - & - \\
\hline
\end{tabular}
ma, AT - Amplitude Total, DP - Desvio Padrão, CV - Coeficiente de Variação (\%). 
com 250 registros $(26,29 \%$ do total). Tal fato se deve diretamente a intensa atividade de queima da biomassa, sendo identificado anteriormente por Fernandes e Correia Filho (2013) e Mollmann Júnior et al. (2013), ambos os estudos mostraram que Atalaia é um dos municípios alagoanos com maiores emissões de poluentes atmosféricos via modelagem numérica. Além do município de Atalaia, quatro outros municípios também apresentaram acúmulos significativos de FC na RMM, por exemplo, Murici (151 FC, 15,88 \%), Rio Largo (140 FC, 14,72 \%), Maceió (96 FC, 10,09 \%) e Marechal Deodoro (86 FC, 9,04 \%). Recentemente, estes municípios foram também identificados no estudo realizado para o estado de Alagoas, onde o aumento dos FC foi associado com variáveis socioeconômicas e ambientais, principalmente o Índice de Desenvolvimento Humano (IDH), constatado por Oliveira-Júnior et al. (2020).

Destaque para Murici que não possui usina e destilaria na região. Nos demais municípios anteriormente citados, existem usinas de produção de açúcar e etanol, por exemplo, Central Leão (Rio Largo - 1894), Uruba (Atalaia - 1906), Santa Clotilde (Rio Largo - 1952), Cachoeira (Maceió - 1959) e Sumaúma (Marechal Deodoro - 1970) (Sindaçúcar-AL, 2017). Embora o município de Murici não possua uma usina ou destilaria instalada, sua área é arrendada para o cultivo de cana-de-açúcar e, assim faz parte do complexo de indústrias de produção sucroalcooleira das cidades vizinhas (Clemente, 2011). Tal fato não ocorre apenas o município de Murici, mas também com os demais municípios que integram a RMM. Ressalta-se que a ocorrência dos FC está atribuída também a outras causas, principalmente, a remoção da vegetação nativa com a finalidade de uso e ocupação do solo para diversas atividades antropogênicas, sobretudo a agricultura familiar e urbanização (Caúla et al., 2016; Clemente et al., 2017; Correia Filho et al., 2019b). Destaque para os municípios de Coqueiro Seco e Santa Luzia do Norte que registraram os menores acúmulos de FC na série temporal, sendo dois FC $(0,21 \%)$ para cada município.

A distribuição anual de FC na RMM foi de 45,28 \pm 22,85 FC. Os valores mínimos de FC indicaram que somente os municípios de Atalaia e Murici se destacam na série temporal. Enquanto que a média e os valores máximos de FC foram verificados nos municípios de Atalaia $(11,9 \pm 8,14 \mathrm{FC})$, Murici $(7,9 \pm 6,86 \mathrm{FC})$, Rio Largo $(6,67$ $\pm 4,47$ FC) e Maceió $(4,57 \pm 3,19$ FC). Em toda a série temporal de FC o DP foi baixo, isso indicou menor variabilidade dos $\mathrm{FC}$ em relação à média. Ao contrário do $\mathrm{CV}$ $\%$, que apresentou percentuais superiores a $70 \%$, isto é, com alta variabilidade temporal dos FC na RMM. Os resultados obtidos foram similares aos obtidos anteriormente por Clemente et al. (2017) e Gois et al. (2020) para o estado do Rio de Janeiro, próximo da região litorânea e com o mesmo bioma, no caso Mata Atlântica. Estes autores atribuem o aumento dos FC em função da dinâ- mica de uso e ocupação antrópica, por exemplo, a substituição do bioma Mata Atlântica por áreas de pastagem, produção de cana-de-açúcar e também os fatores climáticos, como alta temperatura e baixo registro de chuva em algumas mesorregiões do Estado, principalmente Norte e Noroeste (Brito et al., 2017; Sobral et al., 2020). Pereira e Silva (2016) usaram dados de FC do satélite de referência (AQUA_MT) na avaliação espaço-temporal dos FC das mesorregiões do estado da Paraíba e, concluíram que a distribuição temporal dos FC se deve as características climáticas juntamente com as ações antrópicas, praticadas principalmente na agricultura, onde o fogo é utilizado pelos produtores como ferramenta de manejo para criação de pastagens, áreas para o plantio ou para facilitar a colheita. Carneiro e Alburquerque (2019) com base no raio de $4 \mathrm{~km}$ via estimador de densidade de Kernel, verificaram que os maiores registros de FC no município de Teresina, estado do Piauí, foram na área rural entre 2015-2017.

Na Fig. 2, os anos de 2008, 2012, 2015 e 2016 se destacaram na série temporal dos FC, sendo superiores a média do período (> 45 FC) - (Tabela 2). O ano de 2008 é marcado pela atuação da La Niña categorizada como moderada, conforme índice ONI na região 3.4 , e sendo associado ao período chuvoso para o bioma da Mata Atlântica (Correia Filho et al., 2019a), destaque para o acumulado anual de $1500 \mathrm{~mm}$ na RMM em 2008. A produção da cana-de-açúcar depende de altos índices pluviométricos sobre determinada fase de maturação do cultivo (Gomes et al., 2014; Ribeiro et al., 2018). A variabilidade da chuva pode contribui para o aumento da produção das atividades sucroalcooleiras, desta maneira, o que pode diminuir o número de queimadas de cana-de-açúcar (Licks, 2020). Ou seja, de maneira característica, em anos de La Niña são comumente associados à ocorrência de chuvas acima da média (Oliveira Júnior et al., 2012), no entanto o ano de 2012 ( La Niña fraca) apresentou padrão distinto conforme verificado por Correia Filho et al. (2019a), seguido de um acumulado anual de chuva inferior a $1000 \mathrm{~mm}$ na RMM.

Os autores constataram que durante este evento registrou anomalias negativas de chuva no bioma Mata Atlântica, ao qual a RMM está inserida, ao qual este aspecto possivelmente tenha contribuído para a ocorrência de FC. Esta particularidade quanto ao déficit de chuva condiciona o aumento das queimadas sobre a região Nordeste (PROGCLIMA, 2008). Já os maiores totais anuais da série temporal foram associados ao ciclo 2015/2016 que ocorreu o episódio de $E l$ Niño, classificado pelo índice ONI, como Muito Forte. Durante o El Niño, o regime pluviométrico é influenciado de forma negativa (Oliveira Júnior et al., 2012; Lyra et al., 2017), e no caso da RMM o ciclo de 2015/2016 houve uma diminuição dos acumulados de chuva anual (> $1200 \mathrm{~mm}$ ) e, quando as anomalias negativas de chuva estão associadas a temperatura, há também o agravamento da degradação ambiental (Barros 


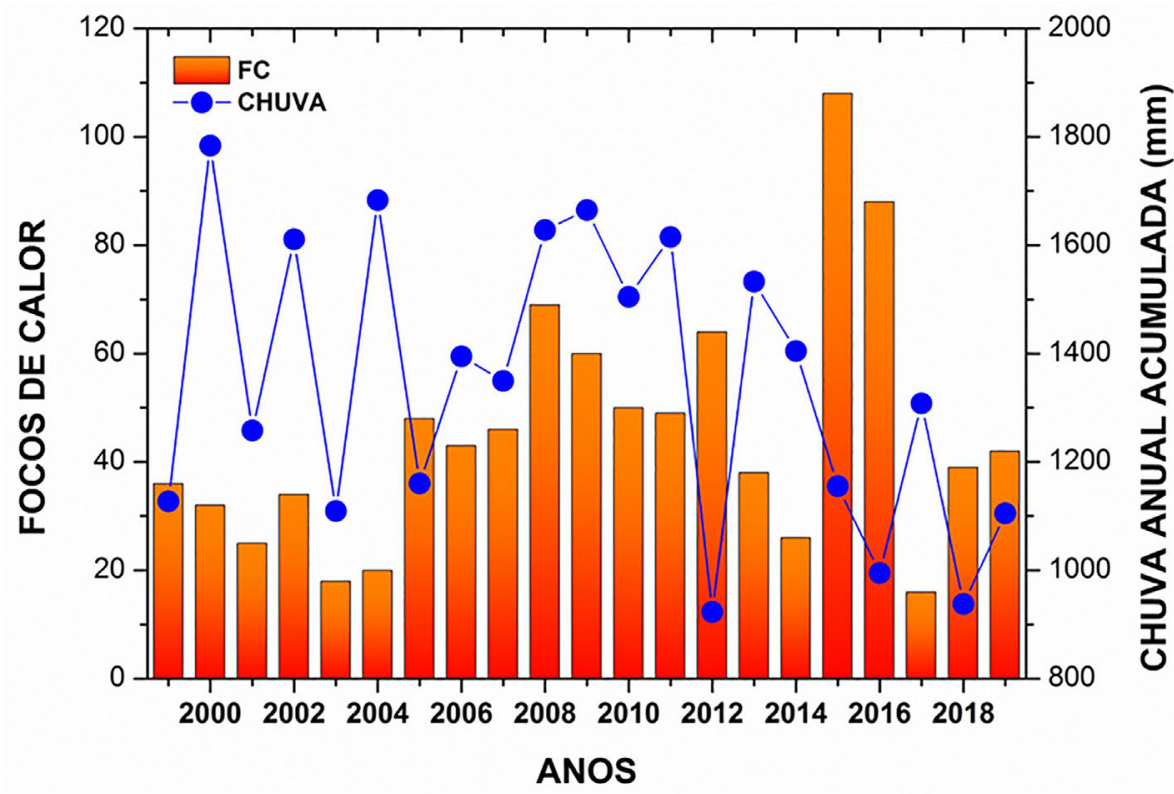

Figura 2 - Acúmulo anual dos FC e da chuva anual (mm) na RMM no período de 1999- 2019.

Santiago et al., 2019), assim potencializa o grau de secura da vegetação no Estado de Alagoas (Alves, 2019).

O evento do ENOS é um dos fatores climáticos que pode contribuir com essa variabilidade dos FC (Mariani et al., 2016; Salazar-Gascón et al., 2018). A Fig. 3 mostrou variabilidade espacial anual do VHI para os anos com maior incidência de FC na série temporal, no caso, os anos de 2008, 2012, 2015 e 2016 destacados anteriormente na avaliação da ED. Com base na distribuição espacial do VHI a maior parte da área da RMM apresentou seca leve $\mathrm{e}$, consequentemente, houve o efeito na dinâmica dos FC. $\mathrm{O}$ ano de 2008, com destaque para os municípios litorâneos ao sul da RMM com VHI anual indicava seca moderada. O VHI na região central e norte da RMM e, principalmente no município de Atalaia foram categorizadoscomo seco, ano de 2012. Já em um periodo de ocorrência de El Niño Muito Forte (ciclos 2015/2016), segundo índice ONI, a RMM apresentou áreas com VHI entre secas severas e extremas. Nem todo dano à vegetação da RMM esteve associado à prática agrícola, sendo registrados também, casos de negligência humana de atear materiais inflamáveis sobre a cobertura vegetal que é devastada por incendios em áreas climaticamente seca (Silveira et al., 2018).

Kogan (2002) afirma que o risco de queimadas está associado com caracteristicas atribuidas ao clima, através do estado saudável da vegetação, uma vez que esta é afetada negativamente, há uma intensificação de incêndios florestais. No entanto, os FC anuais variam de forma relativa com os eventos de ENOS. A detecção de FC durante um ano chuvoso pode ser menor devido à presença de nebulosidade, como também pode ser maior se houver contribuição para desenvolvimento de produção agrícola, que tem como necessidade a prática da queimada (Licks, 2020). Da mesma forma que um ano com chuvas abaixo da média, os FC podem oscilar para menos em função da baixa produção agrícola, como também o VHI possa indicar um risco de intesificação de queimadas e até mesmo incêndio florestal, como aconteceu em 2016 no sul da RMM.

\subsection{Municípios homogêneos de FC}

\subsubsection{Temporal}

A partir da técnica de CA foram identificados três grupos homogêneos de $F C\left(G_{1}, G_{2}\right.$ e $\left.G_{3}\right)$ e um grupo que não se agrupou $\left(\mathrm{N}_{\mathrm{A}}\right)$ na RMM. $\mathrm{O}$ valor de $W$ foi determinado pelo número de grupos relevantes formados (Fig. 4a). O CCC aplicado ao dendrograma obteve o valor de 0,9045 e a linha fenon de $48,33 \%$, segundo a literatura $C C C>0,7$ (Sokal e Rohlf, 1962; Saraçli et al., 2013) indicou que os dados da matriz foram satisfatórios (Fig. 4b).

Destaque para o município de Atalaia (11,9 \pm $8,14 \mathrm{FC}$ ) que não forma grupo homogêneo de $\mathrm{FC}$, sendo grupo $\mathrm{N}_{\mathrm{A}}$ heterogêneo em relação aos demais grupos $\left(\mathrm{G}_{1}\right.$, $\mathrm{G}_{2}$ e $\mathrm{G}_{3}$ ) na RMM. O grupo NA é devido a sua produção sucroalcooleira significativa e, consequentemente maior número de queima da cana-de-açúcar durante o período de colheita (Sindaçúcar-AL, 2017; Oliveira-Júnior et al., 2020). O Grupo $\mathrm{G}_{1}(145,5 \pm 7,77 \mathrm{FC})$ é constituído pelos municípios de Murici e Rio Largo, sendo que tais municípios tiveram maiores registros de FC na RMM atribuídos não só a queima da cana-de-açúcar, mas também a ocorrência de limpeza de pasto e queima de parte do bioma Mata Atlântica para o plantio de cultivo agrícola (Neves 


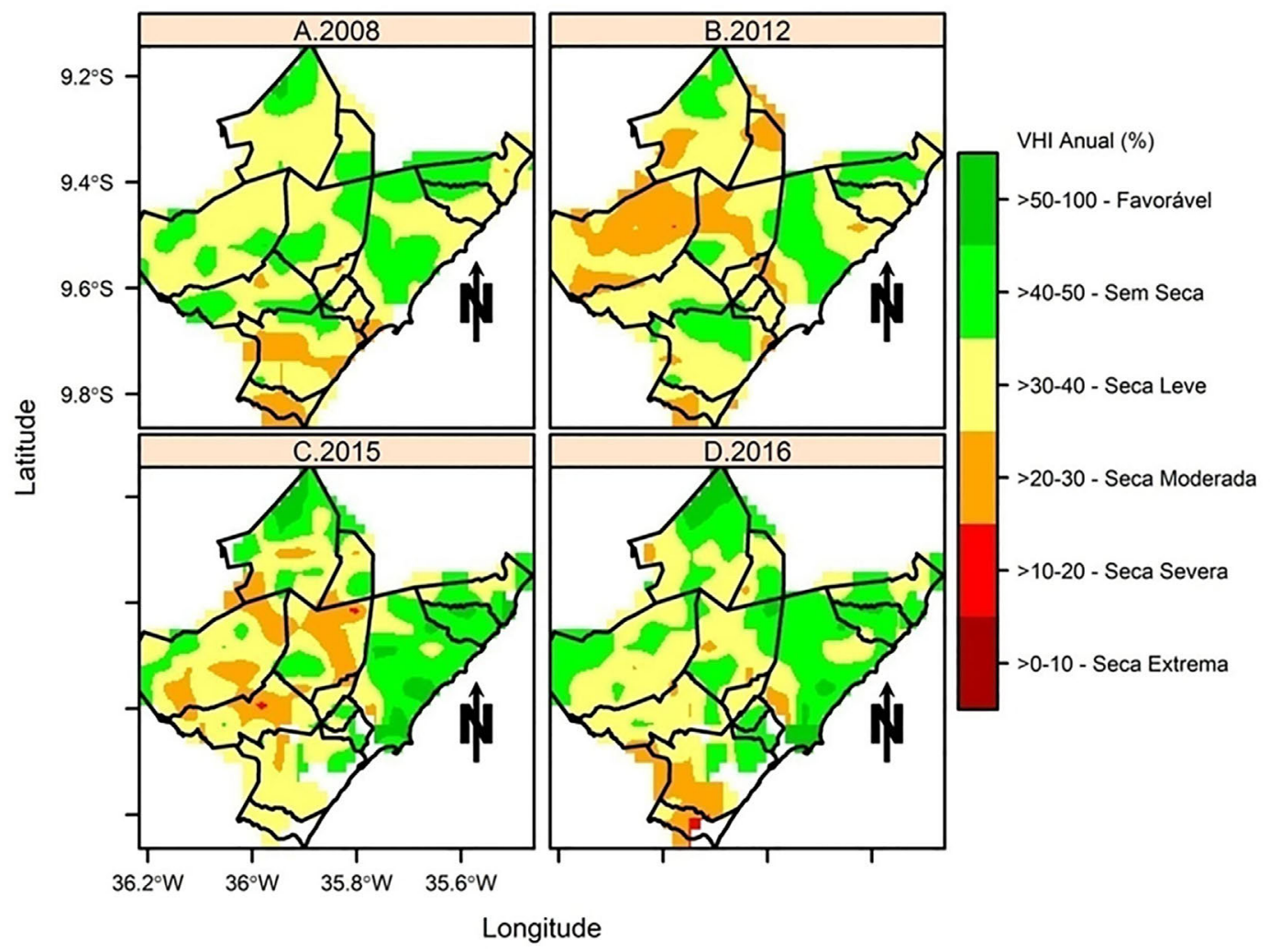

Figura 3 - Distribuição espacial do VHI anual para a RMM para os anos de: (a) 2008, (b) 2012, (c) 2015 e (d) 2016.
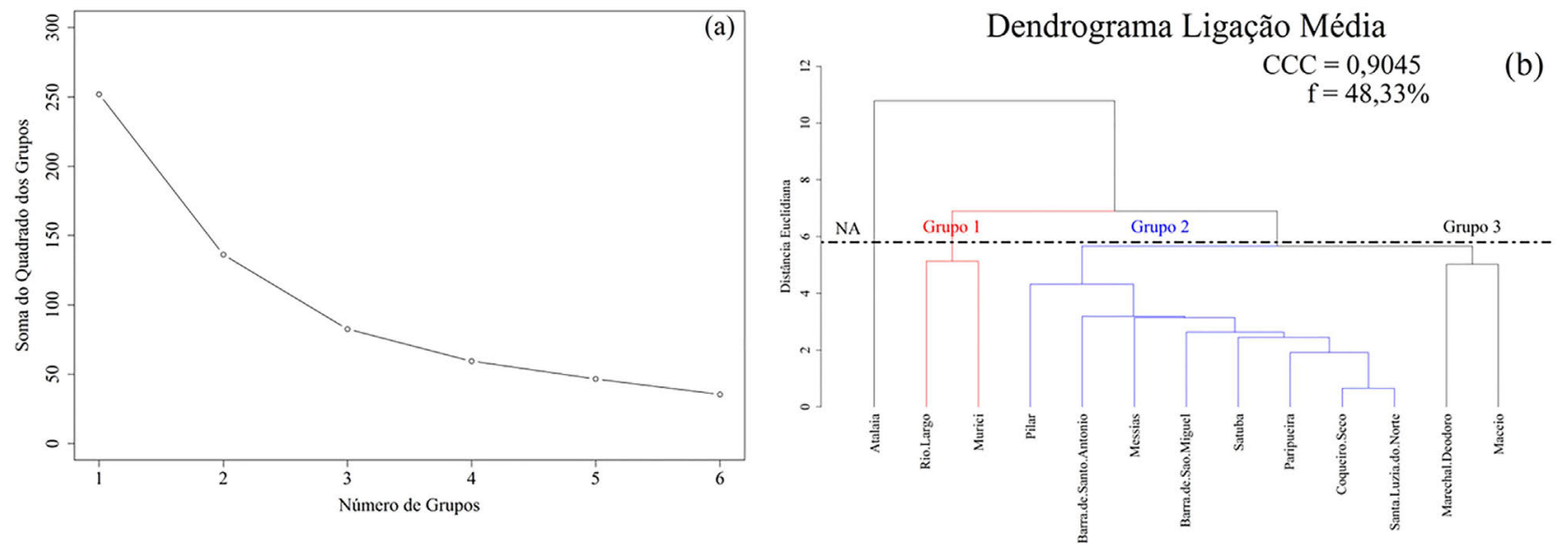

Figura 4 - Número de grupos (a) e Dendrograma (b) com os grupos homogêneos $\left(\mathrm{G}_{1}, \mathrm{G}_{2}\right.$ e $\left.\mathrm{G}_{3}\right)$ e não agrupado $\left(\mathrm{N}_{\mathrm{A}}\right)$ dos $\mathrm{FC}$ da $\mathrm{RMM}$ no período de 1999 a 2019, seguido dos valores do CCC e linha fenon, respectivamente.

et al., 2018). O Grupo $\mathrm{G}_{2}(28,5 \pm 44 \mathrm{FC})$ possui o maior número de municípios da RMM, composto pelos municípios de Coqueiro Seco, Santa Luzia do Norte, Paripueira, Satuba, Barra de São Miguel, Messias, Barra de Santo Antônio e Pilar. Os municípios de Maceió e Marechal Deodoro integram o grupo $\mathrm{G}_{3}(91 \pm 7,07 \mathrm{FC})$. O registro dos FC referente aos municípios que integram o Grupo $\mathrm{G}_{3}$ possivelmente está relacionado ao uso e ocupação do solo resultantes da expansão urbana (Santiago e Barros, 2016;
Correia Filho et al., 2019b) - (Tabela 1) e, ainda também há cultivo de cana-de-açúcar.

\subsubsection{Espacial}

A distribuição espacial dos FCdos grupos homogêneos (Fig. 5) mostrou diferença entre os grupos formados na RMM. As maiores concentrações de FC ocorreram próximas das usinas e destilarias, em virtude da RMM fazer parte da região matriz sucroenergética de Ala- 


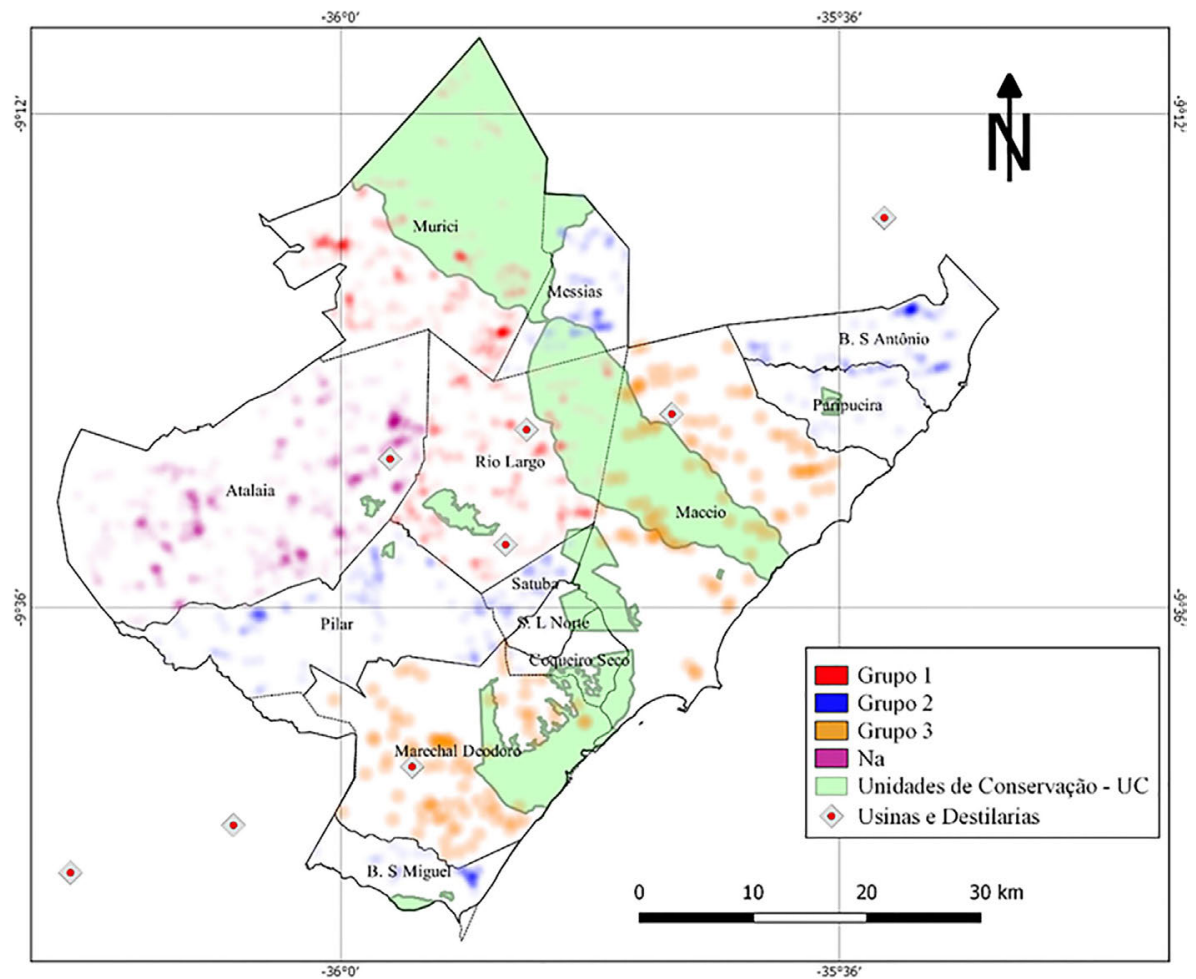

Figura 5 - Distribuição espacial dos FC na RMM de acordo com os grupos homogêneos: $\mathrm{G}_{1}$ (cor vermelha), $\mathrm{G}_{2}$ (cor azul), $\mathrm{G}_{3}$ (cor laranja) e não agrupados (NA, representado pela cor rosa) no período de 1999 a 2019. Os municípios da RMM (delimitados pela linha preta) com a localização das Usinas e destilarias (com o símbolo com círculo vermelho) e as Unidades de Conservação (UC, representadas pela cor verde).

goas (Sindaçúcar-AL, 2017). O Grupo $\mathrm{G}_{1}$ apresentou as maiores concentrações de FC nos setores Oeste e Sul no município de Murici, e nas proximidades da usina em Rio Largo. Vale destacar também FC dentro das UC, principalmente, próximo a região urbana (Oliveira-Júnior et al., 2020). O Grupo $\mathrm{G}_{2}$, com menores registros de FC em relação aos demais grupos, obteve concentrações de FC pontuais, por exemplo, Barra de Santo Antônio, Pilar, Messias e Barra de São Miguel.

O Grupo $\mathrm{G}_{3}$ mostrou concentrações de FC próximas às suas usinas correspondentes, enquanto em suas áreas rurais, esta ocorrência se deve ao avanço antropogênico e adensamento urbano (Correia Filho et al., 2019b). Também são observados FC na região urbana da cidade, inclusive em áreas de UC. Destaque para os FC existentes em Maceió, que se devem as queimadas de canaviais na parte alta da cidade e nas cidades circunvizinhas - (Mollmann Júnior et al., 2013; Correia Filho et al., 2019b), seguido da pratica de limpeza de áreas vegetadas para uso e ocupação da terra (Alves, 2004; Almeida, 2008; Santiago e Gomes, 2016) e não se descarta que alguns FC serem provenientes de unidades industriais (Oliveira-Júnior et al., 2020). Vale ressaltar que a poluição proveniente das queimadas é responsável por problemas de desconforto e problemas patológicos de via respiratórios na RMM, em virtude do regime de vento que atua no Litoral Alagoano (Costa e Lyra, 2012; Mollmann Júnior et al., 2013). O Grupo $\mathrm{N}_{\mathrm{A}}$ apresenta concentração de focos ao longo do município de Atalaia.

Os dados de cultivo de cana-de-açúcar juntamente com os FC dos munícipios da RMM no período de 1999 a 2018 foram correlacionados via diagrama de espalhamento (1:1) - (Fig. 6a). Os coeficientes $R^{2}(75 \%)$ e $r(0,86)$ obtidos mostraram elevada precisão entre ambos os dados, isto é, há alta correspondência entre as áreas de cultivo na RMM e, consequentemente a queima dos canaviais contribuiu no aumento significativo dos FC, sendo anteriormente identificados em outros estudos (Fernandes e Correia Filho, 2013; Mollmann Júnior et al., 2013; Oliveira-Júnior et al., 2020). O padrão relacional entre a área de cultivo da cana-de-açúcar versus os FC na RMM (Fig. 6b) foi avaliado, onde cinco munícipios se destacam em áreas cultivadas de cana-de-açúcar em comparação aos demais munícipios e, claramente contribuíram para variabilidade dos FC na RMM. Destaque para os munícipios de Atalaia (ID 1) - (326.252 ha, 18,40\%) e Rio Largo (ID 11) - (378.857 ha, $21,37 \%)$ com os maiores percentuais e totais de áreas cultivadas de cana-de-açúcar. Os outros munícipios que também se destacaram foram Maceió (ID 5) - (180.372 ha, 10,17\%), Marechal Deodoro (ID 6) (253.212 ha, 14,28\%) e Murici (ID 8) - (200.699 ha, $11,32 \%)$.

A distribuição dos FC mensal dos grupos homogêneos e $\mathrm{N}_{\mathrm{A}}$ correspondem às atividades de queimadas 

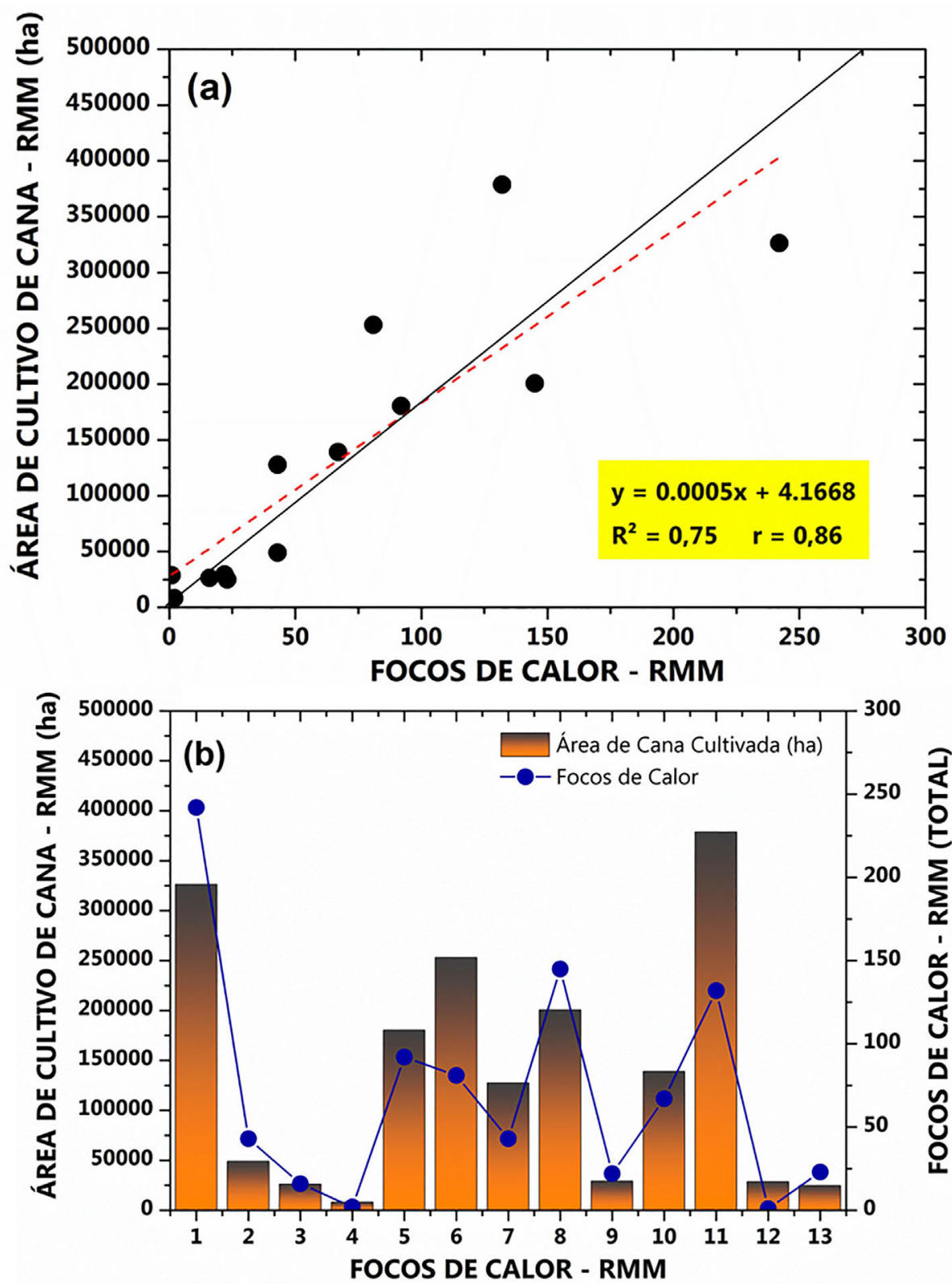

Figura 6 - Diagrama de espalhamento (1:1) (a) e área de cultivo da cana-de-açúcar (ha) versus os FC na RMM (b), no período de 1999 a 2018. Os valores de 1 a 13 correspondem aos ID's dos municípios que compõe a RMM (Tabela 2).

existentes na RMM (Fig. 7). Os FC foram intensificados no período seco e diminuíram de forma significativa no período chuvoso, sendo confirmados na Fig. 2. Os registros de FC são normalmente menores durante a estação chuvosa por conta da nebulosidade, associada à chuva, que dificulta a sua detecção (INPE, 2019). No caso da RMM os meses de chuva se estendem de abril a julho (Oliveira Júnior et al., 2012; Lyra et al., 2014; Nascimento et al., 2018). Outro fator relevante é o período das queimadas em função das colheitas da safra que acontece no período seco (Mollmann Júnior et al., 2013). Durante este período, há uma redução no regime das chuvas em virtude da posição dos ventos alísios que torna a atmosfera mais estável e propicia o aumento da temperatura da superfície (Costa e Lyra, 2012; Carvalhoet al., 2018).

No Grupo $\mathrm{N}_{\mathrm{A}}$ (Fig. 7a), os maiores valores de FC foram entre outubro e janeiro que integram o período seco. Não só por conta das queimadas, mais também pelo avanço de outros cultivos que estão sendo estabelecidos no Estado de Alagoas, por exemplo, o eucalipto, o milho, soja e a pastagem (Ivo et al., 2018). No Grupo $\mathrm{G}_{1}$ (Fig. 7b) os maiores registros de FC, novamente ocorreram em outubro, novembro, dezembro e março, ao contrário do Grupo $\mathrm{N}_{\mathrm{A}}$ associado ao tempo de colheita da safra de 

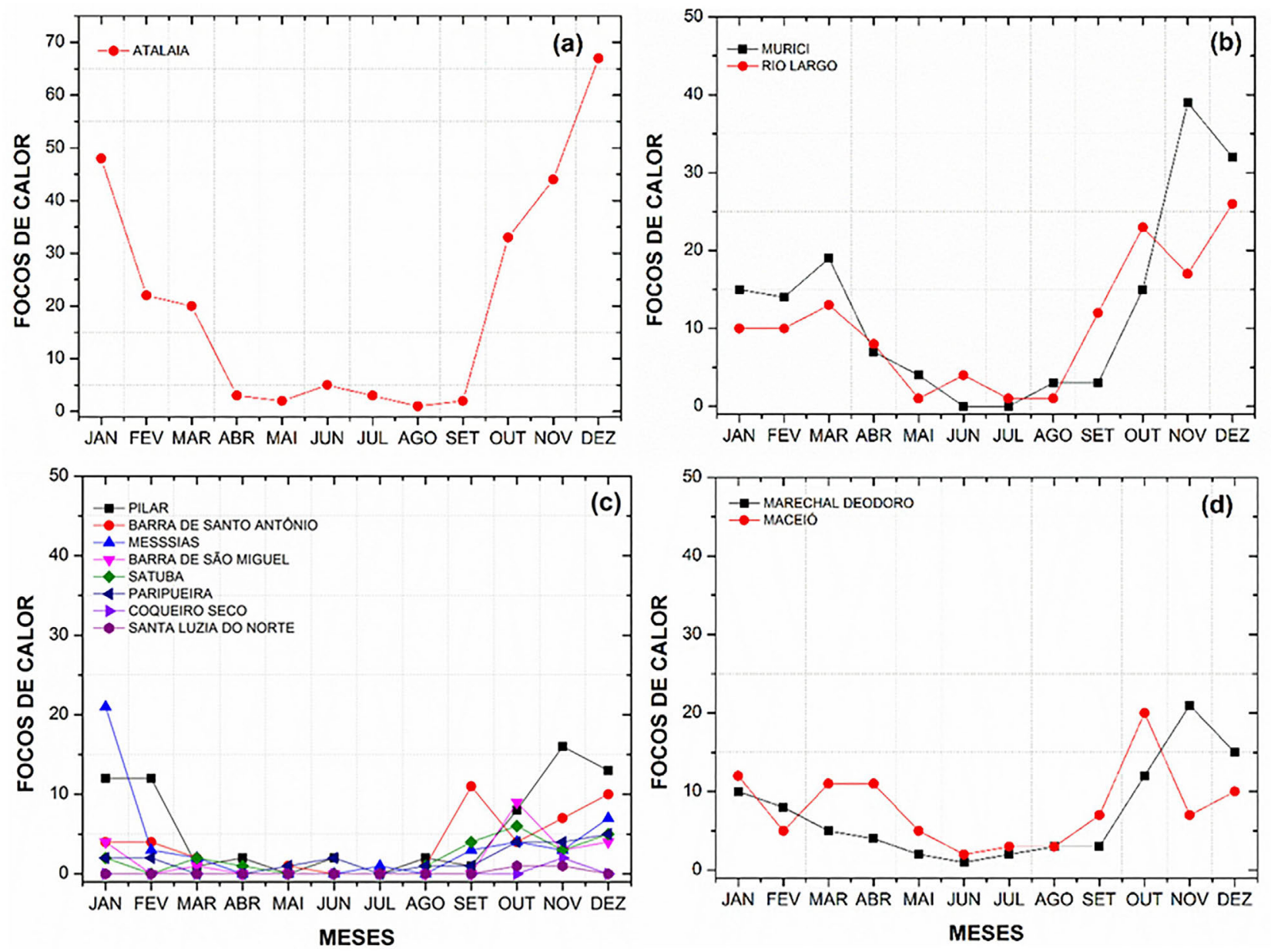

Figura 7 - Distribuição mensal dos $\mathrm{FC}$ do $\mathrm{N}_{\mathrm{A}}$ (a), grupo $\mathrm{G}_{1}(\mathbf{b})$, grupo $\mathrm{G}_{2}$ (c), grupo $\mathrm{G}_{3}$ (d) e no período de 1999 a 2019 .

cana-de-açúcar. O Grupo $\mathrm{G}_{2}$ (Fig. 7c), não há variabilidade mensal dos FC, exceto os municípios de Pilar, Barra de Santo Antônio e Messias, onde os meses que se destacam foram similares ao Grupo $\mathrm{N}_{\mathrm{A}}$ em virtude do cultivo sucroalcooleiro. Já no Grupo $\mathrm{G}_{3}$ (Fig. 7d), maiores registros de FC foram em outubro, novembro, dezembro, janeiro, março e abril, sendo mais longo em comparação aos outros grupos homogêneos e o $\mathrm{N}_{\mathrm{A}}$, uma vez que tais cidades apresentam maior diversidade de cultivo, como o eucalipto (Ivo et al., 2018).

\section{Conclusões}

A análise estatística descritiva mostra que todos os municípios da RMM apresentam alta variabilidade temporal dos FC, com exceção de Santa Luzia do Norte e Coqueiro Seco. A periodicidade da distribuição temporal dos FC é definida entre os maiores registros de $\mathrm{FC}$ pós o período chuvoso, sendo associada à atividade sucroenergética via queima de cana-de-açúcar, principalmente nos munícipios que fazem parte da produção sucroalcooleira do Estado de Alagoas. Claramente, o VHI aponta que os anos com maiores registros de $\mathrm{FC}$ estão associados à degradação da vegetação litorânea, resultantes de condições climáticas de secura e, principalmente pela atuação do ENOS na RMM, particularmente em episódios de $E l$ Niño.

A análise de agrupamento definiu três grupos homogêneos de $\mathrm{FC}$ e o município não agrupado, no caso Atalaia na RMM. O municipio de Atalaia tem os maiores registros de $\mathrm{FC}$, ao qual está relacionado à colheita da safra da canade-açúcar. Os grupos $\mathrm{G}_{1}$ e $\mathrm{G}_{2}$ possuem padrões similares, exceto nos registros dos FC. $\mathrm{O}$ grupo $\mathrm{G}_{3}$ apresenta alta variabilidade dos FC no período chuvoso. Ambos os grupos homogêneos de FC são formados pelas atividades da produção sucroalcooleira, queimadas nas Unidades de Conservação e os incêndios urbanos na RMM.

É recomendada a continuidade do estudo sobre a dinâmica dos FC na RMM, baseado no mapeamento da região via densidade Kernel com raio de influência entre 5 a $10 \mathrm{~km}$, na extração das principais classes de uso e ocupação do solo via NDVI versus FC e, principalmente avaliar a variabilidade dos FC nas UC, APA e Reservas Legais (RL) existentes na RMM. 


\section{Agradecimentos}

Este trabalho foi apoiado pelo Conselho Nacional de Pesquisa e Desenvolvimento Tecnológico (CNPq) com base no Projeto Universal, $\mathrm{n}^{\circ} 424605 / 2018-0$. O primeiro autor agradece ao CNPq pela bolsa de apoio técnico (AT) de $\mathrm{n}^{\circ}$ 371910/2019-6. O segundo autor agradece ao CNPq pela concessão da Bolsa de Pós-Doutorado Júnior (PDJ) de $n^{\circ}$ 161023/2019-3. O terceiro autor agradece ao CNPq pela Bolsa de Produtividade de Pesquisa (nível 2) n 309681/ 2019-7.

\section{Referências}

ALBUQUERQUE, M.A.; FERREIRA, R.L.C.; SILVA, J.A.A.; SANTOS, E.S.; STOSIC, B.; SOUZA, A.L. Estabilidade em análise de agrupamento: estudo de caso em ciência florestal. Revista Árvore, v. 30, n. 2, p. 257-265, 2006.

ALMEIDA, L.G.B.F. Influência da Queima da Palha de Canade-Açúcar na Ocorrência de Doenças Respiratórias em Diferentes Localidades do Estado de Alagoas. Dissertação de Mestrado, Universidade Federal de Alagoas, 88 p., 2004.

ALVES, L.A. Identificação de Impactos Ambientais no Curso Inferior do Rio Pratagy-AL: Imediações do Parque Residencial Benedito Bentes. Dissertação de Mestrado, Universidade Federal de Pernambuco, 82 p., 2004.

ALVES, L.E.R. Análise Espaço-Temporal Da Chuva E Grau De Secura Via Dados Observacionais E Produtos Orbitais Para A Bacia Hidrográfica Do Médio São Francisco. Dissertação de Mestrado, Universidade Federal de Alagoas, 75 p. 2019.

ARAÚJO, J.M., ROSÁRIO, N.M.E. Poluição Atmosférica Associada ao Material Particulado no Estado de São Paulo: Análise Baseada em Dados de Satélite. Revista Brasileira de Ciências Ambientais, v. 55, n. 1, p. 32-47, 2020.

BARROS SANTIAGO, D.; CORREIA FILHO, W.L.F.; OLIVEIRA-JÚNIOR, J.F.; SILVA JUNIOR, C.A. Mathematical modeling and use of orbital products in the environmental degradation of the Araripe Forest in the Brazilian Northeast. Modeling Earth System Environment, v. 5, n. 1, p. 1429-1441, 2019.

BARROS, A.H.C.; ARAÚJO FILHO, J.C.; SILVA, A.B.; SANTIAGO, G.A.C.F. Climatologia do estado de Alagoas. Embrapa Solos. Boletim de Pesquisa e Desenvolvimento (INFOTECA-E), Recife: Embrapa Solos, 32 p., 2012.

BENIN, G.; CARVALHO, F.I.F.; OLIVEIRA, A.C.; MARCHIORO, V.S.; LORENCETTI, C.; KUREK, A.J., SILVA, J.A.G.; CRUZ, P.J.; HARTWIG, I.; SCHMIDT, D.A.M. Comparações entre medidas de dissimilaridade e estatísticas multivariadas como critérios no direcionamento de hibridações em aveia. Ciência Rural, v. 33, n. 4, 657-662, 2003.

BENTO, V.A.; GOUVEIA, C.M.; DACAMARA; C.C.; TRIGO, I.F.A. Climatological assessment of drought impact on vegetation health index. Agricultural and Forest Meteorology, v. 259, n. 1, p. 286-295, 2018.
BRITO, T.T.; OLIVEIRA-JÚNIOR, J.F.; LYRA, G.B.; GOIS, G.; ZERI, M. Multivariate analysis applied to monthly rainfall over Rio de Janeiro state, Brazil. Meteorology And Atmospheric Physics, v. 129, n. 3, p. 469-478, 2016.

CARGNELUTTI FILHO, A.; RIBEIRO, N.D.; REIS, R.C.P.; SOUZA, J.R.; JOST, E. Comparação de métodos de agrupamento para o estudo da divergência genética em cultivares de feijão. Ciência Rural, v. 38, n. 8, p. 2138-2145, 2008.

CARNEIRO, K.F.S.; ALBUQUERQUE, E.L.S. Análise multitemporal dos focos de queimadas em Teresina, estado do Piauí. Revista de Geociências do Nordeste, v. 5, n. 2, p. 31-40, 2019.

CARVALHO, A.L.; MAGALHÃES, I.D.; LYRA, G.B.; SANTIAGO, D.B.; SOUZA, J.S.; TEODORO, I.; FERNANDES, R.C.; LYRA, G. LOPES JUNIOR, J.M. Avaliação climatológica das ocorrências de períodos secos e chuvosos no estado de Alagoas. Caderno de Pesquisa, Ciência e Inovação, v. 1, n. 3, p. 40-50, 2018.

CAÚLA, R.H.; OLIVEIRA-JÚNIOR, J.F.; GOIS, G.; DELGADO, R. C.; PIMENTEL, L.C.G.; TEODORO, P.E. Nonparametric statistics applied to fire foci obtained by meteorological satellites and their relationship to the MCD12Q1 product in the state of Rio de Janeiro, Southeast - Brazil. Land Degradation \& Development, v. 28, n. 3, p. 10561067, 2016.

CAÚLA, R.H.; OLIVEIRA-JÚNIOR, J.F.; LYRA, G.B.; DELGADO, R.C.; HEILBRON FILHO, P.F.L. Overview of fire foci causes and locations in Brazil based on meteorological satellite data from 1998 to 2011. Environmental Earth Sciences, v. 74, n. 1, p. 1497-1508, 2015.

CLEMENTE, C. Aspectos da vida comunitária e da cultura política de um assentamento rural em Murici: reflexões em torno de uma das comunidades visitadas pela equipe da UFU no Projeto Rondon em Alagoas. Revista em Extensão, v. 9, n. 2, p. 136-144, 2011.

CLEMENTE, S.S.; OLIVEIRA JÚNIOR, J.F.; LOUZADA, M.A.P. Focos de calor na Mata Atlântica do Estado do Rio de Janeiro. Revista Brasileira de Meteorologia, v. 32, n. 4, p. 1-9, 2017.

CORREIA FILHO, W.L.F.; BARROS SANTIAGO, D.; OLIVEIRA-JÚNIOR, J.F., SILVA JUNIOR, C.A. Impact of urban decadal advance on land use and land cover and surface temperature in the city of Maceió, Brazil. Land Use Policy, v. 87, n. 1, p. 104026, 2019 b.

CORREIA FILHO, W.L.F.; DOS SANTOS, T.V.; DIOGO, A.M.; DE AMORIM, R.F.C. Diagnóstico da Precipitação e EVI em Dois Eventos de Seca no Nordeste do Brasil. Revista do Departamento de Geografia, v. 35, n. 1, p. 102-112, 2018.

CORREIA FILHO, W.L.F.; OLIVEIRA-JÚNIOR, J.F.; SANTIAGO, D.B.; TERASSI, P.M. B.; TEODORO, P.E.; GOIS, G.; BLANCO, C.J.C.; SOUZA, P.H.A.; COSTA, M.S.; GOMES, B. H.; SANTOS, P.J. Rainfall variability in the Brazilian northeast biomes and their interactions with meteorological systems and ENSO via CHELSA product, Big Earth Data, v. 3, n. 4, p. 315-337, 2019a.

COSTA, G.B., LYRA, R.F.F. Análise dos padrões de vento no Estado de Alagoas. Revista Brasileira de Meteorologia, v. 27, n. 1, p. 31-38, 2012. 
COSTA, L.; NUNES, L.; AMPATZIDIS, Y. A new visible band index (vNDVI) for estimating NDVI values on RGB images utilizing genetic algorithms. Computers and Electronics in Agriculture, v. 172, p. 105334, 2020.

CPTEC - Centro de Previsão do Tempo e Estudos Climáticos. Monitoramento de focos. Disponível em http://queimadas.dgi.inpe.br/queimadas/bdqueimadas/, acesso em 13 de jun. 2020.

DIDAN, K. MOD13A2 MODIS/Terra Vegetation Indices 16Day L3 Global 1 km SIN Grid V006, 2020.NASA EOSDIS LP DAAC. Disponível em http://reverb.echo.nasa.gov/ reverb/, acessado em 04 de abril de 2020.

FERNANDES, R.C.; CORREIA FILHO, W.L.F. Espacialização temporal dos focos de queimadas e de poluentes atmosféricos $\left(\mathrm{CO}, \mathrm{CH}_{4}, \mathrm{NO}_{2}, \mathrm{~N}_{2} \mathrm{O}\right)$ em Alagoas. Ciência e Natura, v. 35, n. 2, p. 287-294, 2013.

FNEM. Fórum Nacional de Entidade Metropolitanas. 2017. Disponível em http://fnembrasil.org/regiao-metropolitanade-maceio-al/, acesso em 13 de jun. 2020.

GAYOSO, J.H.; FILHO A. Desenvolvimento Rural: Políticas Públicas e Desafios Socioeconômicos. Curitiba: Editora Appris, 133 p., 2020.

GOMES, A.C.C.; BERNARDO, N.; ALCÂNTARA, E. Accessing the southeastern Brazil 2014 drought severity on the vegetation health by satellite image. Natural Hazards, v. 89, n. 3, p. 1401-1420, 2017.

GOMES, A.W.A.; SAAD, J.C.C.; BARROS, A.C. Simulação da produtividade de cana-de-açúcar (Saccharum Officinarum L.) na região nordeste do Brasil, utilizando o modelo DSSAT. Irriga, v. 19, n. 1, p. 160-173, 2014.

GOOGLE.Google Earth website. http://earth.google.com/, 2020.

HAIR, J.F.; TATHAM, R.L.; ANDERSON, R.E.; BLACK, W.C.; trad.Adonai Schlup Sant'Anna e Anselmo Chaves Neto. Análise multivariada de dados. Porto Alegre: Bookman, $5^{\text {a }}$ ed., p. 175, 2005.

HUANG, B., BANZON, V. F., FREEMAN, E., LAWRIMORE, J., LIU, W., PETERSON, T. C., SMITH, T. M., THORNE, P. W., WOODRUFF, S.D., AND ZHANG, H.M. Extended reconstructed sea surface temperature version 4 (ERSST v4). Part I: Upgrades and intercomparisons. Journal of Climate, v. 28, n. 3, p. 911-930, 2015.

IBGE - Instituto Brasileiro de Geografia e Estatística. Censo Demográfico 2010 - Área territorial Brasileira. Rio de Janeiro: IBGE, 2020a.

IBGE - Instituto Brasileiro de Geografia e Estatística. SIDRA Censo Agropecuário-2018. Rio de Janeiro: IBGE, 2020b.

IMA - Instituto do Meio Ambiente. Relatórios de Queimadas. Disponível em https://www.ima.al.gov.br/category/queimadas/, acesso em 28 de mar. 2020.

INPE (Instituto Nacional de Pesquisas Espaciais). Banco de Dados de Queimadas. Disponível em http://queimadas. dgi.inpe.br/queimadas/bdqueimadas, acesso em 14 de jun. 2019.

INPE (Instituto Nacional de Pesquisas Espaciais). Perguntas Frequentes. Programa de Monitoramento de Focos. Disponível emml: http://queimadas.dgi.inpe.br/queimadas/portal/informacoes/perguntas-frequentes, acesso em 18 de jun. de 2020 .
INPE (Instituto Nacional de Pesquisas Espaciais). Produção Científica e de Divulgação do Programa Queimadas. Janeiro/2020. Disponível em http:/queimadas.cptec.inpe. br/ rqueimadas/documentos/pub_queimadas.pdf, acesso em 12 de jun. de 2020.

IVO, W.M.P.M.; SANTOS C.C.; ALBUQUERQUE, P. Estoques de carbono do solo em razão da conversão de canade-açúcar em pastagem e eucalipto. In: CONTECC' 2018 - Congresso Técnico Científico da Engenharia e da Agronomia, 21 a 24 de agosto de 2018, Maceió, p. 1-5, 2018.

KARNIELI, A; AGAM, N.; PINKER, R.T.M.; ANDERSON, M.; IMHOFF, M.L.; GUTMAN, G.G.; PANOV, N.; GOLDBERG, A. Use of NDVI and land surface temperature for drought assessment: merits and limitations. Journal of Climate American Meteorology Society, v. 23, n. 3, p. 618-633, 2010 .

KOGAN, F.N. Application of vegetation index and brightness temperature for drought detection. Advance Space Resources, v. 15, n. 11, p. 91-100, 1995.

KOGAN, F.N. Operational space technology for global vegetation assessment. Bulletin American Meteorology Society, v. 82, n. 9, p. 1949-1964, 2001.

KOGAN, F. World droughts in the new millennium from AVHRR based vegetation health indices. EOS, Transactions American Geophysical Union, v. 83, n. 48, p. 557563, 2002.

LICKS, E. B. Viabilidade De Irrigação Para A Produção De Cana-De-Açúcar Nos Municípios De Araçatuba E De Piracicaba. Tese de Doutorado, Universidade de São Paulo, 125 p., 2020.

LIMA, M.; VALE, J.C.E.; COSTA, G.M.; SANTOS, R.C.; CORREIA FILHO, W.L.F.; GOIS, G.; OLIVEIRA JÚNIOR, J.F.; TEODORO, P.E.; ROSSI, F.S.; SILVA JUNIOR, C.A. The Forests in the Indigenous Lands in Brazil in Peril. Land Use Policy, v. 90, n. 1, p. 1-3, 2020.

LYRA, G.B.; OLIVEIRA-JÚNIOR, J.F.; GOIS, G.; CUNHAZERI, G.; ZERI, M. Rainfall variability over Alagoas under the influences of SST anomalies. Meteorology and Atmospheric Physics, v. 129, n. 1, p. 157-171, 2017.

LYRA, G.B.; OLIVEIRA JÚNIOR, J.F.; ZERI, M. Cluster analysis applied to the spatial and temporal variability of monthly rainfall in Alagoas state, Northeast of Brazil. International Journal of Climatology, v. 34, n. 13, p. 3546-3558, 2014.

MARIANI, M., FLETCHER, M. S., HOLZ, A., NYMAN, P. ENSO controls interannual fire activity in southeast Australia. Geophysical Research Letters, v. 43, n. 20, p. 10,891-10,900, 2016.

MAZZOLI-ROCHA, F.; MAGALHÃES, C.B.; MALM, O.; SALDIVA, P.H.N.; ZIN, W.A. FAFFE, D.S. Comparative respiratory toxicity of particles produced by traffic and sugar cane burning. Environmental Research, v. 108, n. 1, p. 35-41, 2008.

MMA - Ministério do Meio Ambiente. Unidades de Conservação: O Que São? Disponível em https://www.mma. gov.br/areas-protegidas/unidades-de-conservacao/o-quesao.html, acesso em 23 de jun. 2020. 
MOLION, L.C.B.; BERNARDO, S.O. Uma revisão da dinâmica das chuvas no Nordeste Brasileiro. Revista Brasileira de Meteorologia, v. 17, n. 1, p. 1-10, 2002.

MOLLMANN JUNIOR, R.A.; SILVA JUNIOR, R.S.; GOMES, H.B.; MOURA, M.A.L. Estudo da dispersão de monóxido de carbono (CO) emitido através da queima de cana-deaçúcar, no estado de Alagoas. Revista Brasileira de Geografia Física, v. 6, n. 3, p. 488-499, 2013.

NASCIMENTO, M.C.; LOMBARDO M.A.; GUIMARÃES JUNIOR, S.A.A. Análise da Vulnerabilidade FísicoAmbiental causada pelas chuvas intensas na Região Metropolitana de Maceió. Caminhos de Geografia, v. 19, n. 67, p. 268-288, 2018.

NEVES, J.A.; SANTOS, C.C.; AMARAL, A.F.C.; SANT'ANNA, S.A.C.; SILVA, P.A.; IVO MELLO, W.P. Emissões de gases de efeito estufa em áreas de cana-de-açúcar colhida crua e queimada. In: Anais 8 Seminário De Iniciação Científica E Pós-Graduação Da Embrapa Tabuleiros Costeiros, 2018.

NOAA/CPC - National Oceanic and Atmospheric Administration/Climate Prediction Center. Cold \& Warm Episodes by Season. Disponível em https://origin.cpc.ncep.noaa. gov/products/analysis_monitoring/ensostuff/ONI_v5.php, acesso em 04 de nov. 2020.

OLIVEIRA JÚNIOR, J.F.; LYRA, G.B.; GOIS, G.; BRITO, T.T.; MOURA, N.S.H. Análise de homogeneidade de séries pluviométricas para determinação do índice de seca IPP no estado de Alagoas. Floresta e Ambiente, v. 19, n. 1, p. 101-112, 2012.

OLIVEIRA, J.G.I.; PAIVA, R.F.P.S.; REIS, M.M.; GOIS, G. Poluição do ar e internações por doenças respiratórias em Volta Redonda, RJ. Revista Brasileira de Ciências Ambientais, v. 55, n. 1, p. 72-88, 2020.

OLIVEIRA-JÚNIOR, J.F.; CORREIA FILHO, W.L.F.; ALVES, L.E.R.;LYRA, G.B.; GOIS, G.; SILVA JUNIOR, C.A.; SANTOS, P.J.; SOBRAL, B.S. Fire foci dynamics and their relationship with socioenvironmental factors and meteorological systems in the state of Alagoas, Northeast Brazil. Environmental Monitoring and Assessment, v. 192, n. 1, p. $654-683,2020$.

OriginLab Corporation. ORIGIN (Pro) - 3.6, Version. OriginLab Corporation, Northampton, 2019.

PEREIRA, J.A.V., SILVA, J.B. Detecção de Focos de Calor no Estado da Paraíba: Um Estudo sobre as Queimadas. Revista Geográfica Acadêmica, v. 10, n. 1, p. 5-16, 2016.

PONTES DA SILVA, B.F., FEDOROVA, N., LEVIT, V., PERESETSKY, A., BRITO, B.M. Sistemas Sinóticos Associados às Precipitações Intensas no Estado de Alagoas. Revista Brasileira de Meteorologia, v. 26, n. 3, p. 323338, 2011.

PROGCLIMA, São José dos Campos: INPE, Ano 9, n. 10, set. 2012. Disponível em http://www.inmet.gov.br/portal/arq/ clima/prognostico-climatico-trimestral/PC1210.pdf, acesso em 18 jun. 2020.

QGIS - QUANTUM GEOGRAPHIC INFORMATION SYSTEM. Quantum GIS Geographic Information System. v. 3.4.6. Open Source Geospatial Foundation Project, 2019.

R DEVELOPMENT CORE TEAM (2020). R: A Language And Environment For Statistical Computing. R Foun- dation for Statistical Computing, Vienna, Austria. https:// cran.r-project.org/bin/windows/base/old/3.6.3/.

RAMOS, A.M.; FREITAS, S.; CONDE, F.C.; LONGO, K.; SILVA, A M.; LUCAS, E.W.M; LUCIO, P.S. Desempenho do Modelo CATT-BRAMS em simulações de transporte de poluentes emitidos por incêndios florestais. Acta de las Jornadas Científicas de la Asociación Meteorológica Española, n. 30, v. 1, 2020.

RIBEIRO, A.R.B.; SILVA, F.F.; MEIRELES, Y.S.; MELO, F.L.; RODRIGUES, R.P. Gestão da sustentabilidade do cultivo de cana-de-açúcar: um estudo de caso no nordeste do Brasil. Revista em Agronegócio e Meio Ambiente, v. 11, n. 3, p. 843-861, 2018.

SALAZAR-GASCÓN, R.E.; MARTINS FERREIRA, C.C. Influência dos eventos extremos ENOS e AMO entre 20032014 no clima e regimes de fogo na GranSabana, Parque Nacional Canaima, Guiana Venezuelana. Revista Brasileira de Climatologia, v. 22, n. 1, 2018.

SANTIAGO, D.B.; GOMES, H.B. Heat islands in the city of Maceió/AL using Orbital Data from Landsat 5. Revista Brasileira de Geografia Física, v. 9, n. 3, p. 793-803, 2016.

SANTIAGO, D.B.; CORREIA FILHO, W.L.F.; OLIVEIRAJUNIOR, J.F.; LYRA, M.J.A.; VILA NOVA, T.S. Comportamento da Saúde Vegetativa do Cerrado Nordestino Brasileiro. Meteorologia e Recursos Naturais: Estudos Aplicados. Campina Grande: EDUFCG, p. 247-255, 2020.

SANTOS, B.A.; OLIVERA, M.D.S.; SILVA, P.N.; SANTOS, J.G.M.; MATTOS, E.V.; REBOITA, M.S. Distribuição espaço-temporal dos focos de calor no Estado de Minas Gerais. Anuário do Instituto de Geociências, v. 42, n. 3, p. 64-84, 2020.

SARAÇLI, S.; DOĞAN, N.; DOĞAN, İ. Comparison of hierarchical cluster analysis methods by cophenetic correlation. Journal of Inequalities and Applications, v. 203, n. 1, p. 1-8, 2013.

SEMARH - Secretaria de Meio Ambiente e Recursos Hídricos do DF. Caderno Técnico: Prevenção e Combate aos Incêndios Florestais em Unidades de Conservação. Brasília: Athalaia, 2004

SETZER, A.; MORELLI, F.; SOUZA, J.C. O Banco de Dados de Queimadas do INPE. Biodiversidade Brasileira, n. 1, v. 1, p. 239, 2019.

SILVA, C.; PORTELLA, A.C.F.; GIONGO, M. Meta-análise de estudos sobre o efeito do fogo nos biomas florestais em relação aos microrganismos fúngicos. Advances in Forestry Science, v. 7, n. 1, p. 931-938, 2020.

SINDAÇÚCAR-AL. Relação das Usinas. Disponível em http:// www.sindacucar-al.com.br/relacao-das-usinas/, acesso em 14 de jun. 2017, 2019.

SOBRAL, B.S.; OLIVEIRA-JÚNIOR, J.F.; ALECRIM, F.B.; GOIS, G.; MUNIZ JUNIOR, J.G.R.; TERASSI, P.M.B.; PEREIRA JUNIOR, E.R.; LYRA, G.B.; ZERI, M. PERSIANN-CDR based characterization and trend analysis of annual rainfall in Rio de Janeiro State, Brazil. Atmospheric Research, v. 238, n. 1, p. 1-104873, 2020.

SOKAL, R.R.; ROHLF, F.J. The comparison of dendrograms by objective methods. Taxon, v. 11, n. 2, p. 33-40, 1962. 
TENÓRIO, R.S.; KWON, B.H., MORAES, M.C.S., LEE, G. Tropical Rainfall Characteristics at the Eastern Coast of South America. Asia-Pacific Journal Atmospheric Science, v. 46, n. 1, p. 415-423, 2010.

TUCKER, C. J. Red and photographic infrared linear combinations for monitoring vegetation. Remote Sensing Environment, v. 8, n. 2, p. 127-150, 1979.

WAN, Z.; HOOK, S.; HULLEY, G. MOD11A2 MODIS/Terra Land Surface Temperature / Emissivity 8-Day L3 Global $1 \mathrm{~km}$ SIN Grid V006.NASA EOSDIS LP DAAC. 2020 .
WARD, J.H. Hierarchical grouping to optimize an objective function. Journal of the American Statistical Association, v. 58, n. 1, p. 236-244, 1963.

ZANINI, A.M.; VENDRUSCOLO, G.S.; MILESI, S.V.; ZANIN, E.M.; ZAKRZEVSK, S.B.B. Percepções de estudantes do Sul do Brasil sobre a biodiversidade da Mata Atlântica. Interciência, v. 45, n. 1, p. 15-22, 2020.

License information: This is an open-access article distributed under the terms of the Creative Commons Attribution License (type CC-BY), which permits unrestricted use, distribution and reproduction in any medium, provided the original article is properly cited. 